\title{
Current situations and advice of supervision of mandatory national standards for water efficiency in China
}

\author{
Zhang Yu-bo ${ }^{1,2}$, Yang Jie ${ }^{1}$, Lin Ling ${ }^{1}$, Hu Hong-ying ${ }^{2}$, Bai Xue ${ }^{1 *}$, Tantai Linlin ${ }^{3}$ \\ ${ }^{1}$ China National Institute of Standardization, No.4 Zhichun Road, Haidian District, Beijing, 100191 \\ ${ }^{2}$ School of Environment, Tsinghua University, Haidian District, Beijing, 100084 \\ ${ }^{3}$ National Academy of Forestry and Grassland Administration, Beijing, 100000 \\ No. 4 Zhichun Road, Haidian District, Beijing, China.
}

\begin{abstract}
China has issued eight mandatory national standards so far to regulate the water efficiency of household products. The State Administration for Market Regulation performs national spot checks yearly on products qualities, which includes water efficiency, meantime it required market regulation bureaucracies of regional levels to strengthen inspection of energy and water efficiency labels from 2019. However, those two levels of inspection neither focus on water efficiency standards nor cover all eight categories of products. Furthermore, there is still space to improve in term of supervision effectiveness, efficiency and database management. For those reasons, this article aims to clarify the deficiencies and propose corresponding advice on the supervision system.
\end{abstract}

\section{Introduction}

Water resources in China seem abundant in term of the total amount of freshwater resources, which is about 2.80 trillion cubic meters, accounting for $6 \%$ of the global amount, only less than Brazil, Russia and Canada in the world. However, the water resources per capita are 2,300 cubic meters, which is a quarter of the world's average level, rendering China one of the most water-poor countries in the world. The water resources supply and demand gap in China widened much, making a prominent problem.

In 2018 , the total water consumption for the country was 601.55 billion cubic meters, among which the domestic sector was 85.66 billion cubic meters, taking $14.3 \%$ of the total. Compared with 2017, domestic water consumption increased by 2.18 billion cubic meters, continuing the ascending trend in recent years [1].

Domestic water is the water used by urban and rural residents for daily life, which flows through water-using appliances such as toilets, showers, spouts, washing machines and water purifiers. Therefore, the development of mandatory water efficiency standards for household water appliances is conducive to improving water-use efficiency and thereby reducing the total amount of domestic water.

\section{Current situation of water efficiency standards}

In 2011, China began to draft mandatory national standards for water efficiency for a wide range of household products. So far, eight standards have been issued and put into use, including electric washing machines, faucets, water closets, urinals, showers, flush valve for water closets, squatting pans and reverse osmosis drinking water treatment purifiers (see Table 1). These mandatory national standards stipulate the minimum allowable values, water-saving evaluation value, range of grades and appraisal method of water-using appliances [2]. The core content of the water efficiency standard is the grades for water efficiency, among which the third level is the minimum allowable values, and the second level is vantage water-saving values, the first level is excellent water-saving values.

Table1. List of the published water efficiency standards

\begin{tabular}{|c|c|c|}
\hline NO. & Serial number & Standards \\
\hline 1 & GB 12021.4-2013 & $\begin{array}{c}\text { Maximum allowable values of the energy, water consumption and grades for } \\
\text { household electric washing machines }\end{array}$ \\
\hline 2 & GB 25501-2010 & $\begin{array}{c}\text { Minimum allowable values of water efficiency and water efficiency grades for } \\
\text { faucets }\end{array}$ \\
\hline
\end{tabular}

\footnotetext{
*Corresponding Author: E-mail: baixue@enis.ac.cn
} 


\begin{tabular}{|c|c|c|}
\hline 3 & GB 25502-2017 & $\begin{array}{c}\text { Minimum allowable values of water efficiency and water efficiency grades for } \\
\text { water closets }\end{array}$ \\
\hline 4 & GB 28377-2012 & $\begin{array}{l}\text { Minimum allowable values of water efficiency and water efficiency grades for } \\
\text { urinals }\end{array}$ \\
\hline 5 & GB 28378-2012 & $\begin{array}{c}\text { Minimum allowable values of water efficiency and water efficiency grades for } \\
\text { showers }\end{array}$ \\
\hline 6 & GB 28379-2012 & $\begin{array}{l}\text { Minimum allowable values of water efficiency and water efficiency grades for } \\
\text { flush valve for water closets }\end{array}$ \\
\hline 7 & GB 30717-2014 & $\begin{array}{c}\text { Minimum allowable values of water efficiency and water efficiency grades for } \\
\text { squatting pans }\end{array}$ \\
\hline 8 & GB 34914-2017 & $\begin{array}{l}\text { Minimum allowable values of water efficiency and water efficiency grades for } \\
\text { reverse osmosis drinking water treatment purifiers }\end{array}$ \\
\hline
\end{tabular}

\section{Current situation of supervision}

According to the "Administrative Measures for Mandatory National Standards" [3] issued in 2020, the supervision for the mandatory standards is mainly carried out through social feedback, the voluntary collection of the drafting department, and other administrative inspections. In China, the market regulation bureaucracies take responsibility for supervising product quality, including water efficiency after the eight standards came into force. Accordingly, China has implemented a water efficiency labelling system nationwide since 2018 by including the toilet in the first batch of products to

$$
\text { pass rate } / \%
$$

implement water efficiency labelling.

\subsection{National supervision and inspection of products quality}

The State Administration for Market Regulation performs national spot checks yearly on products qualities [4]. The ceramic toilet has been spot-checked consecutively since 2007[6], the water efficiency of it was the first time checked from 2014. The spot check results trend was shown in Figure 1, among which smart toilets were checked since 2015 as a result of the market trends, the pass rates of toilets in each national products quality spot check ascending in general.

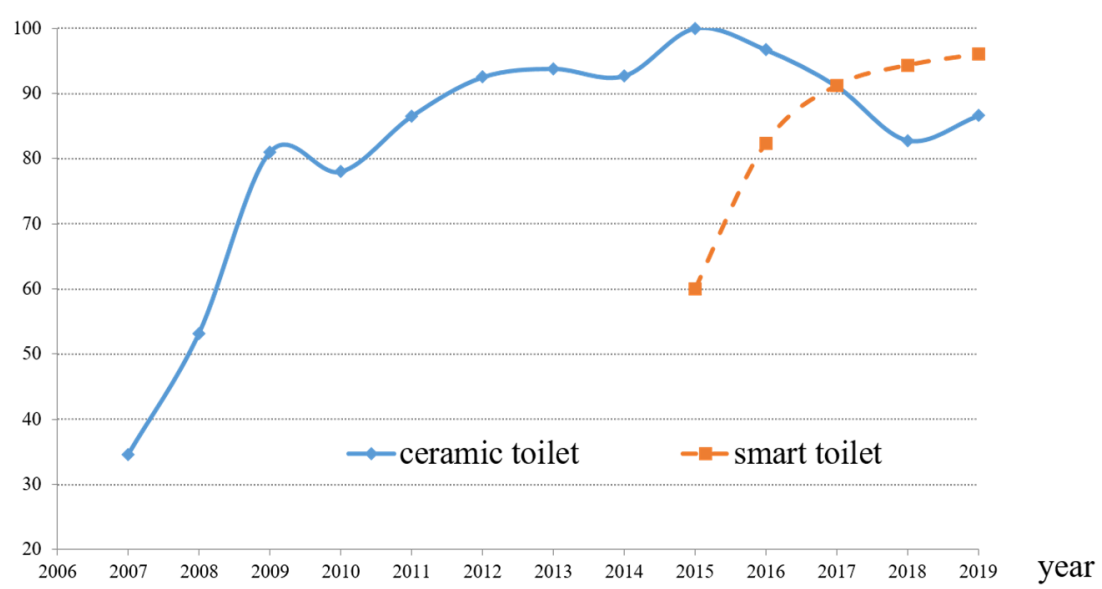

Source: State Administration for Market Regulation

Fig 1. Trend of the pass rate for toilet product quality in national spot checks

In 2015, the State Administration for Market Regulation issued Quality Supervision and Inspection Guideline on Ceramic Toilets (CCGF 401.1-2015) [5] to strengthen the efficiency and effectiveness of national products quality spot checks, to which market regulation bureaucracies at regional levels could refer to as well. The guideline stipulates categories, terms, definitions, sampling method, detailed requirements and testing bases like GB 6952 Sanitary Ceramics and GB 25502 Minimum allowable values of water efficiency and water efficiency grades for water closets [6].

In 2017, the State Administration for Market Regulation performed special products quality spot check on 109 batches of drinking water treatment purifiers, where water efficiency was not checked since the related standard finally came into effect in November 2018[7].

In 2019, the State Administration for Market Regulation performed national products quality spot check on 38 categories of products including 186 batches of ceramic toilets, found that 11 batches failed to meet the 
stated water efficiency level[8]. In the second special spot check of 16 categories of products selling online in the same year, the State Administration spot-checked 50 batches of smart toilets, found that two batches failed to meet the stated water efficiency level [9].

Meantime, regional market regulation bureaucracies perform products quality inspection aperiodically, which might include water efficiency check. In the fourth quarter of 2018, Jiangsu Administration for Market Regulation spot-checked 60 batches of ceramic toilets, found that five batches overstated their water efficiency level.

\subsection{Regional supervision and inspection of water efficiency labels}

In June 2017, "Measures for the management of water efficiency labels" was jointly issued, which triggered the establishment of the water efficiency labelling system [10]. In May 2019, the State Administration for Market Regulation issued a notification that required market regulation bureaucracies of provinces, autonomous regions or municipalities directly under the central government to strengthen supervision and inspection of energy and water efficiency labels [11] (Figure 2). They should submit inspection results by the end of November yearly. The inspection contains two types:

\subsubsection{Label compliance check}

It aims to inspect whether products included in the efficiency index have been labelled legally and appropriately, whether labels have been filed to regulation bureaucracies, and whether labels have been abused for false promotions. It is the critical content of inspection.

\subsubsection{Efficiency compliance check}

It aims to inspect whether products comply with the mandatory standards and whether labels overstate the real efficiency level of products. It is an optional content. Bureaucracies with sufficient resources and expertise could perform if they are willing to do so.

In 2019, several regions performed inspections on the water closets, which is the only product listed in the water efficiency label index currently. Some regions performed the first type of inspection, like Nanjing and Linxia, while some regions performed both two types, like Chaozhou, which spot-checked 25 batches of ceramic toilets in and found two batches failed to meet the sated water efficiency level.

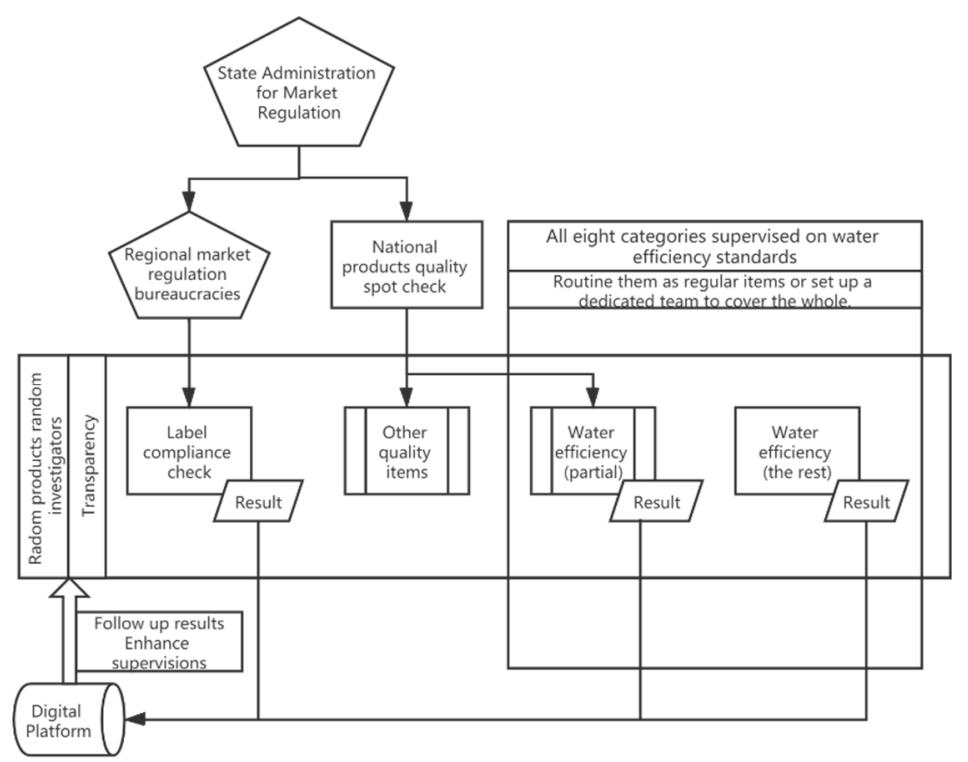

Fig 2. Recommended water efficiency supervision mechanism in China

\section{Deficiency of the current supervising system}

\subsection{Lack of consistency and coverage}

The national products quality spot checks performed by the State Administration for Market Regulation do not always include products subject to mandatory water efficiency standards(Figure 2). In 2020, only four categories of products (electric washing machine, faucets, ceramic toilets, smart toilets, showers) are listed in the yearly national product quality spot-check index [12].

\subsection{Lack of database management system to enhance follow-up work}

Market regulation bureaucracies usually stated that they would push unqualified companies to improve products standards, strengthen supervision on them in the future, and even take legal actions if necessary. However, there is no clarified measure on how to perform supervision on those unqualified companies, and it is a difficult job to keep eyes on them effectively without a sound system. 


\subsection{Limit of effectiveness}

In term of water efficiency labels inspection performed by regional bureaucracies, it seldom helps to supervise the water efficiency given they focus on label compliance check. The inspectors assume the accuracy of labels if qualified institutions issue them. Only part of bureaucracies perform the efficiency check will not help establish the actual status of water efficiency compliance.

\section{Advice on the current supervising system}

\subsection{National digital platform to enhance inspections and follow-ups}

The administrative bureaucracy of standards should establish a national digital platform to gather water efficiency spot-check results (Figure 3). This platform would involve multiple users, allowing producers and sellers to update their products library, market regulation bureaucracies to record check results and plan follow-ups, standards setters to evaluate and update existing standards thereby. In this way, national and regional bureaucracies could select products more targeted that a better balance between coverage and budget is achieved while the quality of sampling probably would improve.

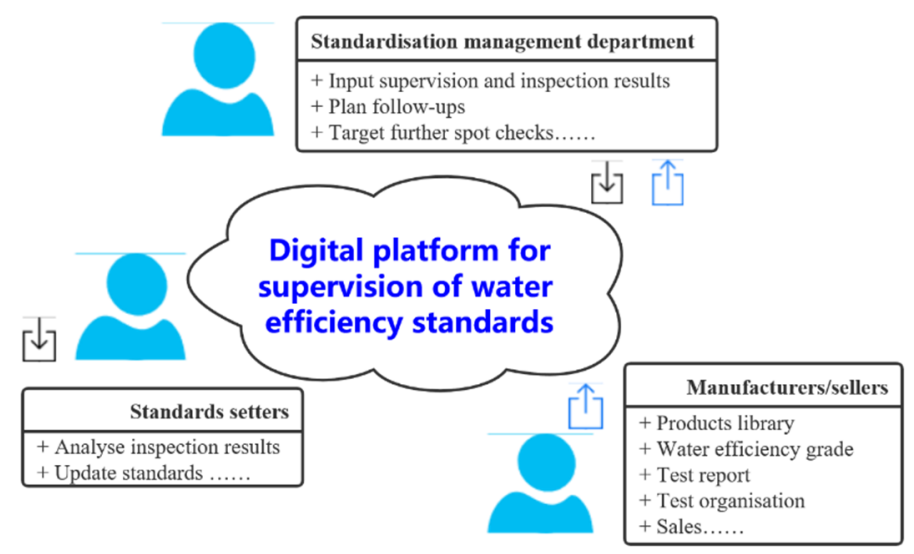

Fig 3. Recommended digital platform for supervision of water efficiency standards

In term of follow-ups, bureaucracies could spot the names of companies obtaining negative results and put more resources on their product status. Following inspection towards them could be recorded to guarantee the performance to turn positive, i.e. spending efforts where it is likely to do the best.

Moreover, this platform would have many other advantages; all users would benefit much. Any level of market regulation bureaucracies could change spot-check priority according to historical results, and learn from typical cases to develop its methodology. The standards setters could analyse the results nationwide to revise standards wisely.

\subsection{Fixed quality check items or an independent inspection team}

Although only toilets are listed in the water efficiency label index that the State Administration for Market Regulation issued a notification nationwide, water efficiency standards are mandatory besides the label management. All eight standards need to be supervised regardless of the efficiency label index. In regional levels, label compliance check will not do much help. At national products quality check, the full coverage cannot be guaranteed.

One possible solution is to fix those eight categories of products as the routine check items and to check water efficiency every year. If this brings much workload or hurt the workflows of the State Administration for Market Regulation, an independent water efficiency inspection team need establishing, and, it could take the responsibility of water efficiency checks on all eight products, thereby decreasing the workload of the state bureaucracy at the same time (Figure 2). Also, the digital platform might enhance the efficiency of spot-check work, thus making it easier to check all eight categories of products.

\section{Acknowledgments}

This research is supported by the Dean's Fund of China National Institute of Standardization (NO. 542020Y-7456).

\section{References}

1. Ministry of Water Resources of the People's Republic of China. 2018 China Water Resources Bulletin [Z]. 2019-07-12.

2. Zhang Yubo, Bai Xue, Hu Mengting. Study on the Evaluation Index System for Implementation Effect of Minimum Allowable Value of Water Efficiency and Water Efficiency Grades Standards [J]. Standard 
Science, 2020, (1), 11-14.

3. State Administration for Market Regulation. Administrative Measures for Mandatory National Standards [Z]. 2020-01-06.

4. State Administration for Market Regulation. Interim Measures for Product Quality Supervision and Spot Check Management [Z]. 2019-11-21.

5. State Administration for Market Regulation. Quality Supervision and Inspection Guideline on Ceramic Toilets（CCGF 401.1-2015) [Z]. 2015-04-29.

6. Duan Xianhu. Analysis Report on the Results of the National Supervision and Spot Check on the Quality of Ceramic Toilet Products in 2012 [J]. Ceramics, 2013(06):40-41.

7. General Administration of Quality Supervision, Inspection and Quarantine of the People's Republic of China. Circular of the General Administration of Quality Supervision, Inspection and Quarantine on the Special Spot Inspection of the National Supervision of Water Purifier Product Quality in 2017[Z]. 2017-09-12.

8. State Administration for Market Regulation. The national supervision and random inspection of the quality of 38 kinds of products such as the restraint system for children of motor vehicles in 2019[Z]. 2020-01-22.

9. State Administration for Market Regulation. The second batch of 2019 special inspections on the quality of 16 kinds of online-sold products such as toys[Z]. 2020-03-20.

10. National Development and Reform Commission, Ministry of Water Resources of the People's Republic of China, General Administration of Quality Supervision, Inspection and Quarantine of the People's Republic of China. Measures for the management of water efficiency labels[Z]. 2017-0913.

11. State Administration for Market Regulation, National Development and Reform Commission, Ministry of Water Resources of the People's Republic of China. Notice on strengthening supervision and inspection of energy efficiency and water efficiency labels[Z]. 2019-06-06.

12. State Administration for Market Regulation. 2020 National Product Quality Supervision and Spot Check Plan[Z]. 2020-05-07. 